\title{
Exploration and Practice of Teaching for Artificial Intelligence Public Elective
}

\author{
Junsong $\mathrm{Li}^{1}$, Yubo Jia ${ }^{3}$, Na Zhang ${ }^{4}$, Xianchuang $\mathrm{Su}^{5}$ \\ Department of Computer Science \& Technology \\ School of Information \\ Zhejiang Sci-Tech University \\ Hangzhou, China \\ ${ }^{1}$ ljscg@sina.com \\ 3 jiayubo1964@163.com \\ 4hangna@zstu.edu.cn \\ 5 xianchuangsu@gmail.com
}

\author{
Ning Gui ${ }^{2}$ \\ Department of Digital Media Technology \\ School of Information \\ Zhejiang Sci-Tech University \\ Hangzhou, China \\ 2 ninggui@gmail.com
}

\begin{abstract}
This paper analyzes the features of artificial intelligence public elective (AIPE) and proposes the teaching objectives for student in terms of these features. By teaching practice, the teaching reform is explored in the teaching content and the teaching mode of AIPE as well as the assessing method for student achievement. According to the feedback from students, the effects of teaching reform are analyzed and summarized. Moreover, the problems which need to be further explored in the future are presented.
\end{abstract}

Keywords-Artificial intelligence, Public elective, Teaching reform, Teaching practice, Team learning, Assessing method

\section{INTRODUCTION}

Artificial Intelligence (AI) is developing as a comprehensive frontier discipline. AI which is developed by interpenetration of Computer Science, Control Theory, Information Theory, Neurophysiology, Psychology, Linguistics and so on is still in state of craftsmanship [1]. Many colleges and universities have been treating $\mathrm{AI}$ as a branch of computer science and opening AI course for senior class undergraduates and/or postgraduates [2-4]. AI has been an important course especially for students of Computer, Automation and other Information related majors $[5,6]$. In the past dozen years, the development in the teaching content, the teaching model and method of AI course has achieved fruitful results with teaching it as a professional course or a professional elective course for students of Information related majors [7-10].

The AI course plays an important role in the knowledge hierarchy of undergraduates increasingly. On the one hand, since the emerging of AI in Dartmouth Conference in June 1956, it has got rapid development. As being born for more than 50 years, the AI, as a new cross-disciplinary, has been more and more attention, and the ideology, theory, method and technique of AI have permeated into many areas of science and technology and various aspects of human life [11]. On the other hand, AI has both engineering and scientific goals [12]. With the development of various science technologies and the widely interdisciplinary application, the requirements for AI technology have been increased extremely. Meanwhile, for AI teaching, it is a rapid developing course with emerging of new ideas, new concepts, new theories, and new technologies continually. The teaching contents and teaching methods for AI should keep up with the current development, and AI can be studied and applied by more students in different disciplines.

More and more students in non-information disciplines are eager to understand and master the field of AI which is full of allure and challenge with the emerging of intelligent automobile, intelligent robot, smart mobile-phone, intelligent response system and other intelligent products. Reference [13] recognized that artificial intelligence public elective (AIPE) can benefit students in many aspects, such as logical thinking ability, association ability, extending knowledge scope of students and so on. Thus, we open AIPE for all students with any major in our university.

This paper analyzes the characteristics of the AI course as public selective course and discusses the teaching targets for students. The selection of teaching contents, design of teaching mode, improvement of assessment model for student achievement and so on are explored in this paper. Teaching effects, as well as the problems need to be studied in the future are analyzed and summarized through the feedback information of students in multiple teaching practices.

\section{CharaCteristics AND TEACHING TARgETS OF AIPE}

\section{A. Characteristics of AIPE}

AI course has its distinctive features in the development, contents and process of teaching as well as teaching condition. First, in perspective of teaching development, the expert system, neural network, robotology, pattern recognition and other core curriculums related to AI were mainly opened to doctoral students from the late 1980s to early 1990s in domestic key universities. After the mid 1990s, the above courses were opened to postgraduates. These courses emphasized on theories and abstract contents. In the lately 10 years, although the barycenter of education and teaching for AI was gradually shift down, it mostly only concentrated in teaching for students who major in computer, information or information related majors. Thereby, this situation hinders the fusion of advanced ideology of AI with other specialties and makes it fall behind the social development. 
Then, in perspective of the knowledge of the curriculum content, AI is interdiscipline. The research area of AI is very extensive, such as Automated Theory Proving, Automatic Programming, Game, Natural Language Understanding, Expert System, Intelligent Search, Data Mining, Machine Learning, Robot, Neural network, Pattern Recognition and so on. In addition, the subject basis of AI refers to Cognition Science, Information Science, Computer Science, Logistics, Noetic Science, Neuroscience, Behavioristics, Mathematics, linguistics, Philosophy and so on. At present, the AI subject is developing. How to select the teaching contents of AIPE to suit for the development of society for college and university students in multi-specialties becomes a proposition since AI involves extensive research fields and subject areas.

In the teaching process, the unduly strict and theorization teaching model and/or single boring inculcated teaching fashion based on entirely textbooks are not suitable for the present demand of teaching and education. The college and university students prefer to acquire new knowledge which has practicality and they are interested in. Therefore, it is important to guide the students to autonomic learning and make creative learning by cooperation of them as the students in different specialties have interests in different branches of AI.

Different schools have different teaching environments and teaching conditions. In our university, the overall teaching hours of AIPE is only 32 hours. The students who select AIPE come from various specialties and most of their major are not related to computer and/or information science. Most of them acquaint with the AI through science fiction and movie.

\section{B. Teaching Targets of AIPE}

We proposed a basic train objective for AIPE based on the above characteristics to maximum the learning efficiency of students.

\section{1) Mastering of knowledge}

After studying AIPE, students should know the developing process and research application domain of AI. In addition, students should understand and grasp the conceptual framework, the basic thought as well as the characteristics of the multiple domains knowledge related to AI. Moreover, they should understand or grasp knowledge to a certain depth in at least one domain of AI.

\section{2) Training of ability}

After studying AIPE, the abilities of students, such as access to information, thesis writing, translation, design and application, presentation, self-learning, cooperation, innovation and so on, should be improved.

\section{TEACHING REFORM FOR AIPE}

We configure the main teaching contents for AIPE to reach the above basic targets through investigating students and combining with teaching experience of other colleges and universities. In addition, we adopt a variety of teaching methods and means, such as team learning, to improve the teaching efficiency. Finally, a set of evaluation mechanism which needs the participation of students and teachers was designed to evaluate student achievement.

\section{A. Teaching Contents}

If the teaching contents of AIPE are not selected appropriately, It will be likely to make teaching and learning in trouble, namely some teaching contents which students do not care about are selected or some teaching contents which they want to learn are not involved in AIPE. Therefore, we configure the teaching contents of AIPE which are suitable for students through matching the existing teaching contents with their demand of this course. Ten main teaching contents are selected from AI teaching contents of other colleges and universities. These ten contents are: (1) Basic introduction of AI; (2) Knowledge representation technology; (3) Problem solving method; (4) Fundamental inference technology; (5) Inaccuracy inference; (6) Prolog language; (7) Expert system; (8) Machine learning; (9) Artificial neural network; (10) Artificial intelligence game. Sixty-two students from different disciplines in our university are randomly selected to evaluate the demand level of these ten teaching contents. The score range is 0 to 5,0 means no requirement and 5 means great requirement. Let ORV denote the overall requirement value for teaching content that the students give. The statistical results are showed in Fig.1. As shown in Fig.1, contents 1 through 3 have higher requirement, contents 9 and 10 have lower requirement, and the others have medium requirement.

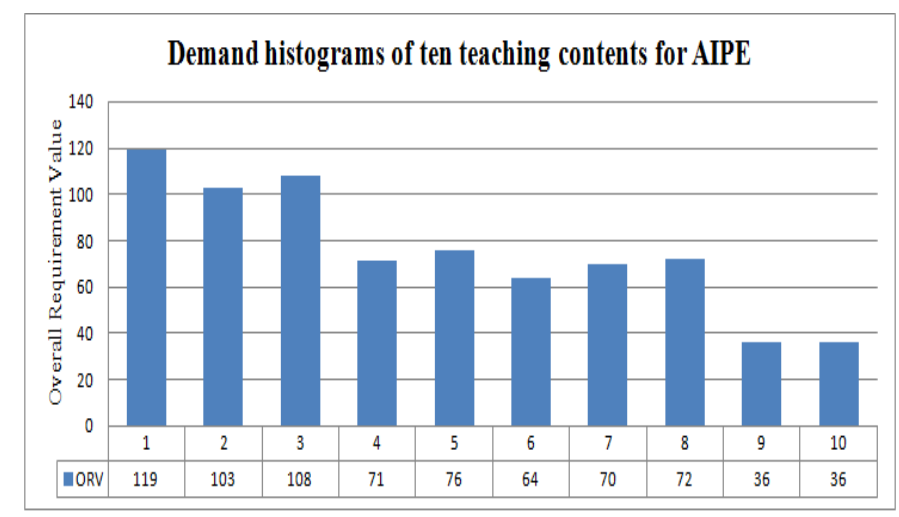

Fig. 1. Demand histograms of ten teaching contents for AIPE

In addition, we conduct an investigation for the basic situation of the students who participated in AIPE. The results showed that these students have the following characteristics:

(1) $95 \%$ these students are sophomore and junior;

(2) The percentages of these students who possess the computer, mathematics and programming language related knowledge are $100 \%, 100 \%$ and $94 \%$ respectively;

(3) These students' major are various;

(4) These students' requirements for AIPE have dispersion characteristics.

The results of the above investigation showed that students have certain preference for different teaching contents of AIPE and they possess the fundamental knowledge which enables them to learn this course without much difficulty. 
In order to achieve teaching goals within limited time (32 teaching hours), we allocate new teaching module and sequence of teaching contents by integrating the existing teaching contents and meeting the actual education environment of our university. Fig. 2 shows that new teaching contents for AIPE consist of three knowledge modules in which fundamental knowledge is principal module while advanced application and optional content are horizontal expansion modules. The fundamental knowledge mainly focuses on teaching background knowledge and concepts as well as principle ideology of AI. The advanced application introduces new developments and applications of AI according to the discipline features of our university. The optional content is used to make students select one of the sub-modules and form a team to study and discuss it in the classroom according to their major and/or interest. In addition, the teaching hours and teaching contents for each teaching module can be adjusted slightly according to different elective students in different semester. Thus, the teaching contents for AIPE can be more accurately and reasonably organized.

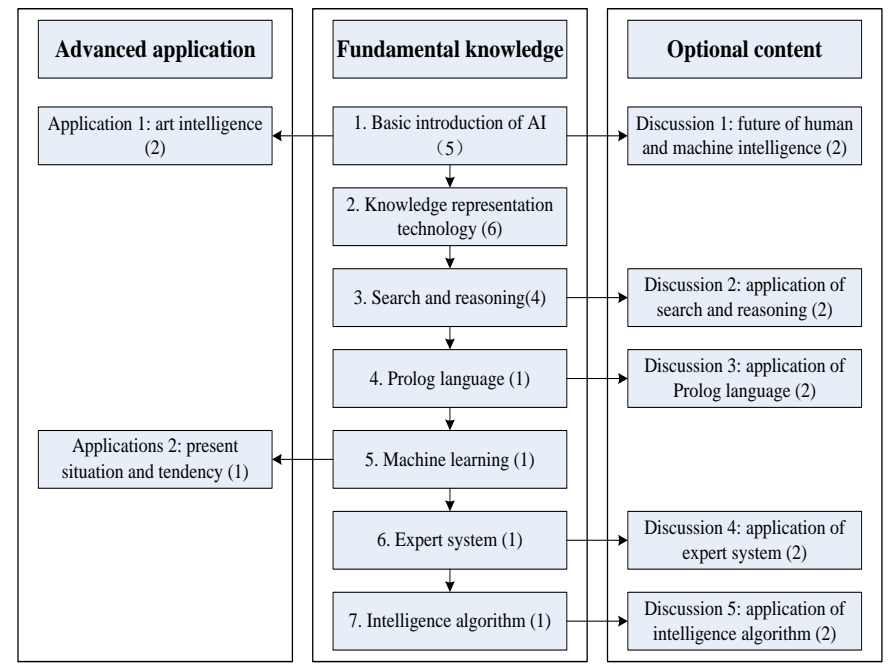

Note: The number in brackets indicates teaching hours.

Fig. 2. Configuration sequence diagram of teaching content for AIPE

\section{B. Teaching model}

A teaching framework for AI was designed to maximize the study efficiency of students and improve their multifaceted ability. As shown in Fig.3, the entire teaching framework is composed of teaching contents, teaching module (including knowledge selection, teaching method and practical application), evaluation mode and ability training. The teaching and learning are merged to one entirety through the interrelation and support of each sub-modules. This kind of teaching framework is not only suitable for the student major in information related disciplines but also the student who is not in information related disciplines. The teaching model in this framework can directly influence the ability training of students.

There are three modules which are fundamental module, interesting module and creative application module in the knowledge selection section. This design can make students acquire knowledge in breadth and depth. These three modules matchup with fundamental knowledge, advanced application and optional content of the teaching contents respectively. The knowledge of fundamental module has to be mastered. The interesting module can be gradually adjusted according to the interest of students and AI development. For innovation application module, each student needs to select one subject from the optional content. Then, the students are organized to a team carrying out learning activity autonomously under the guidance of the teacher.

For the teaching method, multiple kinds of teaching styles can be selected based on the different teaching contents. Question teaching and scenarios teaching are often used. For example, the teacher can make the students pairwise to play the seven coins separation game when teaching the game tree search. Then, the teacher guides students how to ensure that they are not failed in games. At last, the theoretical knowledge of the game tree search is taught. After that, students are allowed to verify the theory through playing this game again. Case teaching and project teaching are mainly used to explain the specific application of knowledge so that students can master and understand the knowledge contents easily. For instance, we adopt a real medical treatment expert system to analyze each knowledge points of the expert system. Autonomous teaching and seminar teaching are adopted for optional teaching contents. Students autonomously study the course using the after-school time. So, the student can understand the key points of the knowledge and knowledge application deeply by using seminar teaching in class. The most important thing is that several teaching methods can be used together instead of usingthem independently. For example, we not only adopt case teaching for expert system contents but also supply a skeleton system to students. Students are guided to use skeleton system and design an expert system through autonomous teaching method. At last the seminar teaching is used to analyze the characteristic of the expert system designed by students and modify this expert system by themselves.

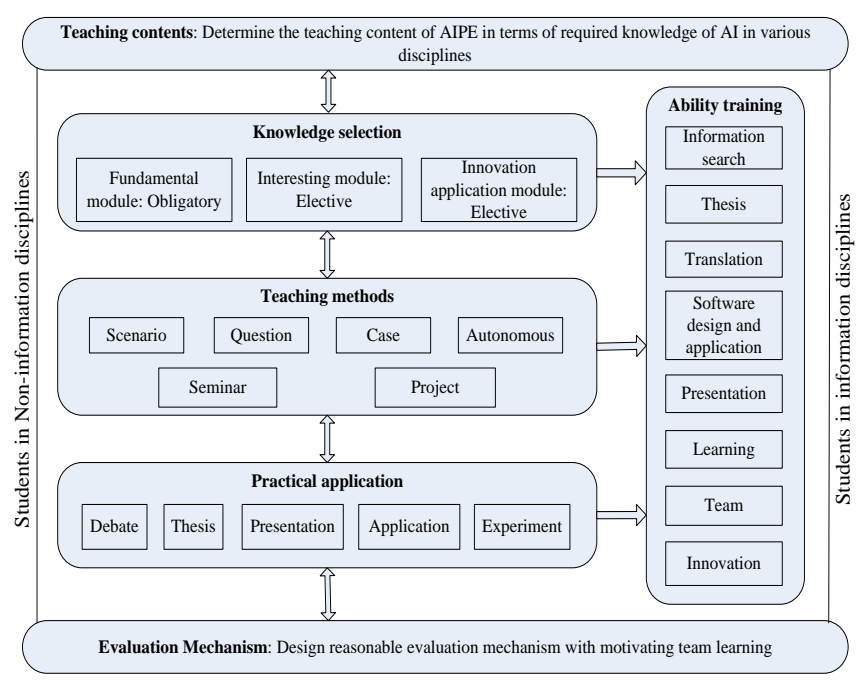

Fig. 3. Teaching framework for intelligence course for AIPE

The practice application is mainly used to the optional contents. The specific methods for practice application include the debate, thesis, presentation, application (e.g. application 
analysis) and experiment. After introducing the general situation of AI, the students who select Discussion 1 are divided into two groups to discuss the future of human and machine by debating. We ask the students to submit a paper about the contents of autonomic learning at the ending of the course, which aim is mainly to train the habit and attitude of students for scientific research. Presentation is an effective practice teaching activity. Teachers can adjust the deviation in the process of study according to the mistakes in the presentation of the student. The application is mainly used to guide the students to exhibit the application of AI in their discipline area. The experiment can enhance the understanding and application of the knowledge. Such as, the Prolog language has the characteristic of presentation. After introducing the utilization of integrated development environment (IDE) for Prolog, the students are guided to do experiment, namely program to solve the simple logistic problem by themselves.

The number of students participate in the course should be controlled between 20 and 40 in order to introduce the team learning mode. Five learning teams are constructed based on five teaching contents of optional content module. And the teams are assembled freely. Then, the teacher reallocates rationally to form the ultimate teams. This teaching mode has the following characteristics:

(1) Different disciplines are mutually complementary, which can benefit the emerging of innovative ideas through colliding of thinking mode from different disciplines.

(2) The application of AI can be discussed based on the disciplines of students, which will benefit them on deep understanding and mastering of the AI application for their own disciplines.

(3) It can benefit the students on learning how to arrange the work and cooperate with each other in the process of team studying. At the same time, students can master the information search, information organization, information extract and finally they make the information become their own knowledge to improve their ability of solving problem.

The ultimate objective for application of the above teaching models is not only to make students master knowledge but also to enhance the ability of students in all aspects. For example, in order to perform very well in the discussing class, students have to collect kinds of datum and information, study them, hands-on practice and exhibit their achievement at last. In this process, the abilities of students in information search, translation, software design and application, presentation, learning, team and innovation can be improved

Moreover, we strength the software development for computer assisted instruction (CAI), such as animation teaching software used to show internal mechanism of Prolog search strategy and genetic algorithm. We provide students with relevant material for practice, such as IDE and handout of Prolog, skeleton software for expert system and so on. The internet communication platform is established. These efforts can benefit the study and improve the study efficiency of students.

\section{Evaluation mechanism}

A good evaluation mechanism for student achievement can not only assess the study effect and efficiency of students appropriately, but also can inspire their internal motivation for autonomic learning. It is unscientific and unfair to evaluate the learning effect and efficiency of students according to one test score especially for the students participate in this course who come from different disciplines and have different knowledge background. We bring the learning attitude and effort level of the students into the assessment mechanism in order to inspire their autonomic learning. The team learning model is introduced to this course. Therefore, it is difficult for the teacher to evaluate the learning attitude and effort level of the students since most of the team learning occurs after class. So, the assessment model which is only determined by the teacher is given up. A new assessment model is considered, namely teachers and students are all involved in the evaluation process to evaluate the learning effect and efficiency of the students.

A multi-dimensional assessment method for learning effect is established for AIPE. Formula (1) represents the overall score of one student. There are 3 parts in formula (1): regular scores, team score and paper score which are shortly written as $\mathrm{R}, \mathrm{T}$ and $\mathrm{P}$ respectively. In addition, $a_{1}, a_{2}$ and $a_{3}$ denote the percentage of each part in the assessment. At the same time, $a_{1}+a_{2}+a_{3}=1$ is guaranteed and the value of them can be adjusted according to the teaching condition. The team score is composed of team show score and personal learning score, they are denoted as $T_{s}$ and $P_{l}$ respectively. In addition, $b_{1}$ and $b_{2}$ denote the percentage of each part in team score. At the same time, $b_{1}+b_{2}=1$ is guaranteed and the value of them can be adjusted as well. $\mathrm{R}, \mathrm{P}, T_{s}$ and $P_{l}$ are scored using centesimal system. $\mathrm{R}$ is scored according to the attendance rate and classroom questioning. $\mathrm{P}$ is the score for thesis. $\mathrm{R}$ and $\mathrm{P}$ are evaluated by the teacher. After a team demonstrate their learning outcomes, $T_{s}$ is scored by other students who are not in this team according to if they can benefit from this team. $P_{l}$ is scored by the team leader according to the learning attitude and effort level of each member. The $\boldsymbol{P}_{l}$ of the team leader is scored by the teacher for the team leader contacting and communicating with the teacher frequently. This kind of assessment mode can effectively inspire students to participate in team learning and improve their learning efficiency.

$$
a_{1} R+a_{2} T+a_{3} P=a_{1} R+a_{2}\left(b_{1} T_{s}+b_{2} P_{l}\right)+a_{3} P
$$

\section{EFFECT OF CURRICULUM REFORM}

We carried out investigation for the student participating in this course after the end of the course in order to obtain the actual effect of curriculum reform. The investigation results are shown as follows:

(1) The students master some AI knowledge which can benefit them much through learning of this course. 
2) The learning time in and after class are basically equal. At present, the teaching contents are appropriate and not too difficult for students. However, the contents need fine-tuning for students from different disciplines.

3) Team learning is good for the students. Multiple teaching methods are used in the learning process, which are of great help for students to improve their various abilities. Students want to acquire more shared learning information.

4) More or less the various abilities of students are improved in this course. Their interesting for AI is enhanced.

5) The assessment system is relatively reasonable. However, if there were the collusion of students for $\mathrm{T}$ score in the scoring stage, the overall score would be unfair.

Students agree that the curriculum contents, team learning mode, various abilities training, multiple kinds of teaching methods revolutions are effective according to the above summary of their learning experience. And, some problems are also reflected, such as the collusion problem in scoring process and the share of learning information. All of these need to be solved and improved in the subsequent teaching.

\section{CONCLUSION}

The AI course is gradually opened to students whose major is not information related disciplines in various colleges and universities. This article presents the teaching system and contents of AI which are suitable for the demand of current society and the study capacity of students. We need to explore appropriate classroom teaching methods to promote and guide the awareness of interdisciplinary and cooperation of the students who have different focus and thinking mode because of different discipline background. We explored the teaching model for AIPE and studied the effectiveness of the new teaching model. The results show that the students' comprehensive ability can be improved by guiding the students to use the resource autonomously and participate in the team learning. Meanwhile, some deficiencies (see section IV) are found by teaching the AIPE for several times. These deficiencies demonstrate the future exploration direction for us.

\section{ACKNOWLEDGMENT}

The authors acknowledge the support of Class Teaching Reform Project of Zhejiang Sci-Tech University (No. 11120432311204) and Zhejiang Provincial advantage Professional Construction Projects: Computer Science and Technology (No. sys201210).

\section{REFERENCES}

[1] Gao J, He QM, “Artificial intelligence basis,” Higher Education Press (Second Edition), 2008. (Chinese)

[2] Chen BF, Cai ZX, Liu LY, "Exploration of Innovative Teaching Mode of Artificial Intelligence Elaborate Course," Computer Education, 2010, vol. 19, pp. 27-31. (Chinese)

[3] Ren XP, Ren QX, Guo F, "Research on Artificial Intelligent Series Courses of Graduate Students," Computer Education, 2010, vol. (19), pp. 90-92. (Chinese)

[4] Ji X,Li LS, "The Research on Teaching of Artificial Intelligence for Undergraduate Students,” The Science Education Article Collects, 2013, vol. 244, pp. 91-92. (Chinese)

[5] Xiao CJ, Li JF, Yang H, "Exploration and Practice of Teaching Methods Reformation of Artificial Intelligence Course," Modern Computer, 2013, vol. 9, pp. 32-34. (Chinese)

[6] Shen Q, Kong FQ, "Teaching Exploration of Artificial Intelligence Course based on Aerospace Major," Science and Technology Innovation Herald, 2014, vol. 29, pp. 155-156. (Chinese)

[7] Kumar, A.N., "Using robots in an undergraduate artificial intelligence course: an experience report," Frontiers in Education Conference, 2001. 31st Annual. IEEE, vol. 2, pp. T4D-10-14.

[8] Kumar, A.N., "Three years of using robots in an artificial intelligence course: lessons learned," Journal on Educational Resources in Computing (JERIC), 2004, vol. 4(3), pp. 2-18.

[9] Chen AB, "Practice and Exploration on the Course Teaching of Artificial Intelligence," Journal of Zhuzhou Institute of Technology, 2006, vol. 20(6), pp. 137-139. (Chinese)

[10] Fang M, Tian Y, Xu J, Fang XM, "Exploration and Thinking on Teaching Practice Reform of Artificial Intelligence," Chongqing and World · Academic Edition, 2013, vol. 30(10), pp. 80-81. (Chinese)

[11] Chu QW, "A philosophical view of artificial intelligence," Wuhan University of Technology, 2014. (Chinese)

[12] Nilsson, N.J., "Artificial intelligence: a new synthesis," Morgan Kaufmann, 1998.

[13] Wang XH, Wang SQ, "Teaching Exploration of Public Elective: Introduction to Artificial intelligence," Fujian Computer, 2011(5), pp. 209-210. (Chinese) 